Communications in Physics, Vol.25, No. 1 (2015), pp. 67-74

DOI:10.15625/0868-3166/25/1/5601

\title{
MECHANISM TO DETECT PESTICIDE RESIDUES IN TEALEAVES BASED ON CdZnSe/ZnS TERNARY ALLOY QUANTUM DOTS
}

\author{
NGUYEN NGOC HAI, NGUYEN HAI YEN, DUONG THI GIANG, DINH HUNG CUONG, \\ NGUYEN DUC NHAT, PHAM THU NGA, AND DAO TRAN CAO \\ Institute of Materials Science, Vietnam Academy of Science and Technology, \\ 18 Hoang Quoc Viet Road, Cau Giay, Hanoi, Vietnam
}

E-mail: haidhsphn@gmail.com

Received 01 December 2014

Accepted for publication 26 March 2015

\begin{abstract}
In this report, we present the optical properties of the biosensors fabricated from CdZnSe/ZnS quantum dots. The optical properties such as absorption and emission of the ternary quantum dots before and after coupling with the protein molecules like streptavidine (SA) and acetylcholinesterase enzymes (AChE), forming a biosensor structure, will be presented. In particular, the changes in luminescence intensity according to the $\mathrm{pH}$ value of the solution environment containing biosensor have been considered, before and after the presence of pesticides. The changes in luminescence intensity of the biosensor after the presence of pesticide over time from 2 seconds to 26 minutes were also surveyed. We have carried out the tests to determine the trace amounts of commercial pesticides like Motox 5EC, containing 5\% cypermethrin and Tungatin 10 EC, containing 10\% abamectin, on the real samples of tealeaves. Some characteristics of the relationship between composition, structure, and special optical properties of ternary alloy quantum dots will also be presented. These studies open up the potential applications of ternary quantum dots for agricultural production.
\end{abstract}

Keywords: Pesticide, biosensors, ternary alloy quantum dots, photoluminescence.

\section{INTRODUCTION}

Tea is the most popular beverage throughout the world. Among the factors limiting the quality and quantity of tea production, the role of insect pests is important. Management of pests in tea plantations has largely depended on the use of conventional, neuron toxic, broad-spectrum synthetic chemical pesticides [1]. Organophosphorus (OP) and carbamates (CM) compounds are widely used in agriculture because of the efficiency for insect killing, easy synthesis, and low cost [2]. The above pesticide residues are harmful to the environment, human health, and animals through the nervous system poisoning by the way of inhibiting the activity of AChE, the most important enzyme involved in nerve transmission [3]. Colloidal semiconductor quantum dots (QDs) such as binary $\mathrm{CdSe}$ and $\mathrm{CdTe}$, whose band gaps are continuously tuned by changing sizes, offer a new powerful tool for use in multicolor bio-imaging, bio-sensing, light-emitting diodes, photovoltaic devices, lasers, and quantum computing devices [4]. Instead of controlling the size of QDs, 
the formation of ternary alloy quantum dots (TQDs) can be an alternative approach to tune their energy band gaps, typically using ternary or quaternary compositions. In these multi-compositional QDs, the band gap energy of the TQDs is determined by the combination of their chemical stoichiometry and particle size. TQDs could be achieved by changing the constituent cation/anion precursor amounts. Recently, several groups have demonstrated that TQDs have many advantages over binary QDs. Some work reported give the finding that TQDs may represent a new route to achieve the next generation of QDs [5]. The widely tunable emissions of $\mathrm{Cd}_{\mathrm{x}} \mathrm{Zn}_{1-\mathrm{x}} \mathrm{Se}$ alloy QDs in the range of wavelengths from 534 to $620 \mathrm{~nm}$, are reported [6]. The compositions of TQDs were estimated based on their sizes and band gap energy.

In recent years, there have been many reports on the use of biosensor in the detection of pesticides with very low levels of residues in agricultural products such as vegetables and apple, as well as in the bottled drinking water [7,8]. In this report, we present the results of extensive research of $\mathrm{CdZnSe} / \mathrm{ZnS}$ TQDs in biosensor to detect two types of pesticides of Motox 5EC, containing 5\% cypermethrin (OP), and Tungatin $10 \mathrm{EC}$, containing $10 \%$ abamectin $(\mathrm{CM})$ on tealeaves. The combinations of quantum dots (QD) and enzymes form biosensors because enzyme AChE atcs as the indicator and is determined indirectly by using acetylthiocholine (ATCh). ATCh is a very strong hydrolyte in the presence of $\mathrm{AChE}$ enzyme and used as an indicator for the activity of $\mathrm{AChE}$ enzyme [9]. The principal role of $\mathrm{AChE}$ is the termination of nerve impulse transmission at cholinergic synapses by rapid hydrolysis of the neurotransmitter acetylcholine (ACh) ? each molecule of AChE degrades about 25000 molecules of ATCh per second. Inhibition of AChE enzyme accumulates ATCh, affects the impairment on nerve functions $[9,10]$.

\section{EXPERIMENTAL}

\section{II.1. Synthesis of CdZnSe core and CdZnSe/ZnS core/shell TQDs}

The CdZnSe TQDs were synthesized with a constant precursor ratio of $\mathrm{Cd}_{0.2} \mathrm{Zn}_{0.8} \mathrm{Se}$. This method is adapted from an existing work for CdSe quantum dots [5,6]. We used ultra-pure nitrogen flow for all synthetic routes. The molar ratio of the precursors for a typical synthesis of $0.5 \mathrm{mM}$ $\mathrm{Cd}_{0.2} \mathrm{Zn}_{0.8} \mathrm{Se}$ alloy nanocrystal QDs was $\mathrm{Cd} / \mathrm{Zn} / \mathrm{Se}=0.2 / 0.8 / 3.33$; TOPO/HDA $=55 / 45$. Firstly, TOP-Se precursor was injected into a flask under vigorous stirring at temperatures of $100^{\circ} \mathrm{C}$ and heated up to $190^{\circ} \mathrm{C}$. After injecting TOP-Zn, the temperature was raised to $270^{\circ} \mathrm{C}$ and TOP-Cd precursor was injected. The nucleation of CdZnSe TQDs cores started shaping quickly at $260{ }^{\circ} \mathrm{C}$. The temperature was maintained in the range of $260-290{ }^{\circ} \mathrm{C}$ for 20 minutes and then we obtained $\mathrm{Cd}_{0.2} \mathrm{Zn}_{0.8} \mathrm{Se}$ core TQDs. Secondly, a $\mathrm{ZnS}$ shell was covered on the core as follows. A mixture of $0.25 \mathrm{mM} \mathrm{CdZnSe} \mathrm{TQDs,} \mathrm{and} \mathrm{TOPO} \mathrm{and} \mathrm{HDA} \mathrm{was} \mathrm{evacuated} \mathrm{for} \mathrm{an} \mathrm{hour} \mathrm{at} 50 \mathrm{C}$. The shell growth took place at $220 \mathrm{C}$ with an amount of $\mathrm{S}$ of $0.115 \mathrm{ml}$. The shell thickness was about 2, 4, 6 monolayers (ML), depending on the amount of Zn precursor and S solution [11].

\section{II.2. Biosensor fabrication}

The TQDs were surface-modified by MPA in order to assure water solubility and streptavidin (SA) molecules were attached to the TQDs [12]. AChE enzymes (EC 3.1.1.7, activity unit: $500 \mathrm{U} / 0.7 \mathrm{mg}$ ) and S-acetylthiocholine iodide (ATChI) are purchased from Sigma-Aldrich. The ATCh was prepared from ATChI $[12,13]$. Based on coulomb interaction, the AChE was conjugated to form sensitive TQDs/SA/AChE biosensors. TQDs/SA and AChE were mixed and incubated at $37^{\circ} \mathrm{C}$ for 10 minutes. Different amounts of the pesticides were added to the same 
corresponding amount of ATCh $(2 \mu \mathrm{mol})$, and the mixture is added to the biosensor solution, incubated at $37^{\circ} \mathrm{C}$ for $20 \mathrm{~min}$. The $\mathrm{pH}$ values of the initial solutions are around 7.1 - 7.3.

\section{II.3. Tealeaves processing}

Two pesticides were sprayed on the tea plants with concentrations of 0.71 and $1.12 \mathrm{ppm}$ based on the calculated ratio by the manufacturer with a dose for specific crop acreage. The recommended time after spraying to harvesting is 14 and 7 days for Motox 5EC and Tungatin $10 \mathrm{EC}$, correspondingly. We kept the tea tree under sunny weather conditions and picked tealeaves every 2 days and 1 day for two types, cut the leaves with the same area, then we soaked in the same volume of distilled water and shook vigorously for 1 hour at room temperature. Finally, we extracted the solution for using in the experiments to detect residues.

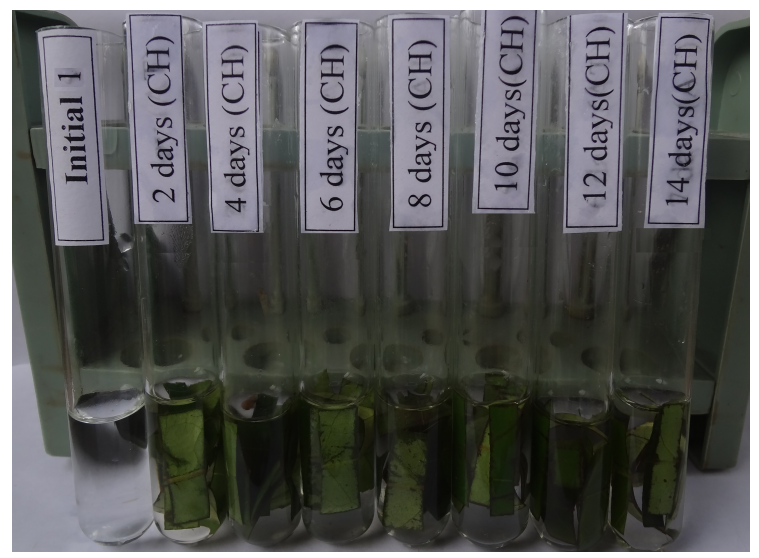

(a)

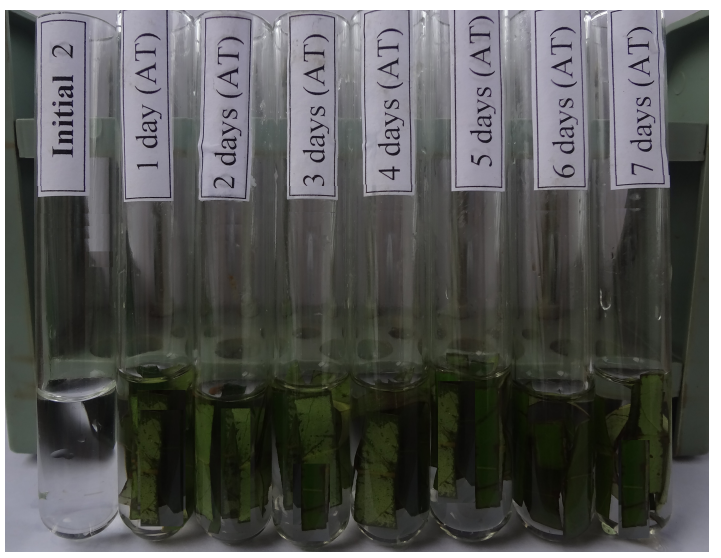

(b)

Fig. 1. Tea leaves washing solutions with (a) Motox 5EC, containing 5\% cypermethrin $(\mathrm{OP})$ and (b) Tungatin $10 \mathrm{EC}$, containing $10 \%$ abamectin $(\mathrm{CM})$

\section{II.4. Pesticides}

Motox 5EC, containing the active ingredients of $5 \%$ cypermethrin $\left(\mathrm{C}_{22} \mathrm{H}_{19} \mathrm{Cl}_{2} \mathrm{NO}_{3}\right)$ that is the organophosphorus compound (OP): less toxic to warm-blooded animals, fish, toxic to bees, and crabs. This pesticide effects prevent some pests of rice, vegetables, and tea, such as leaf bugs, thrips, aphids brown, green hoppers, borers, gummy worms, grasshoppers, aphids, leaf insects and omnivorous worms. Tungatin $10 \mathrm{EC}$, containing 10\% abamectin (C48H72O14 or C48H70O14) that is carbamate (CM) compound. This insecticide produced by biotechnology, extracted from fluid avermitilis streptomyces fungus. There are highly effective against insects, spider, aphids, beetles, red spider in tealeaves.

\section{II.5. Analytical equipments}

The size of the core QDs and the shell thickness are determined by a transmission electron microscope (TEM) JEOL JEM 1010 operating at $100 \mathrm{kV}$. An X-ray diffractometer Siemens 


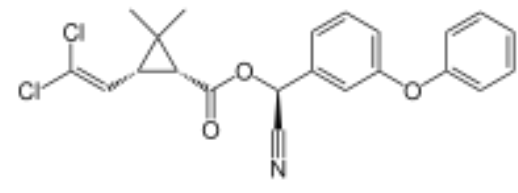

(a)

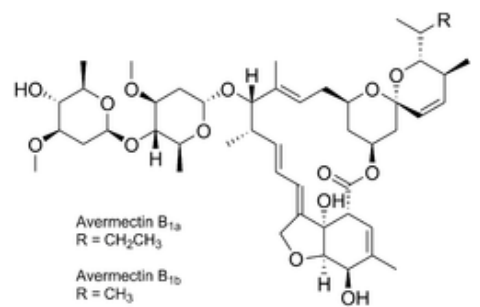

(b)

Fig. 2. Structure of cypermethrin (OP) (a) and Structure of abamectin (CM) (b)

D5005 is used to determine the crystal structure. The elemental analysis is carried out using a Nova NanoSEM 450 scanning electron microscope (SEM) equipped with an energy dispersive $\mathrm{X}$-ray spectrometer (EDS). The absorption characteristics of the QDs were measured by an UVvisible absorption pectrophotometer (Shimadzu, UV-1800). The PL decays were analyzed with a PM Hamamatsu R5600U and a Tektronix TDS 784A scope. In addition, the pH was measured electrically by WTW Inolab pH720.

\section{RESULTS AND DISCUSSION}

TEM images of $\mathrm{Cd}_{0.2} \mathrm{Zn}_{0.8}$ Se TQDs illustrated in Fig. 3 show their quasi-spherical shape. The average sizes are measured to be about 3.36-5.10 $\mathrm{nm}$ and about 5.19-7.07 $\mathrm{nm}$ for the core TQDs grown for $20 \mathrm{~min}$ and the core/shell TQDs, respectively. These core/shell TQDs create the large surface area for conjugating of biology agents.

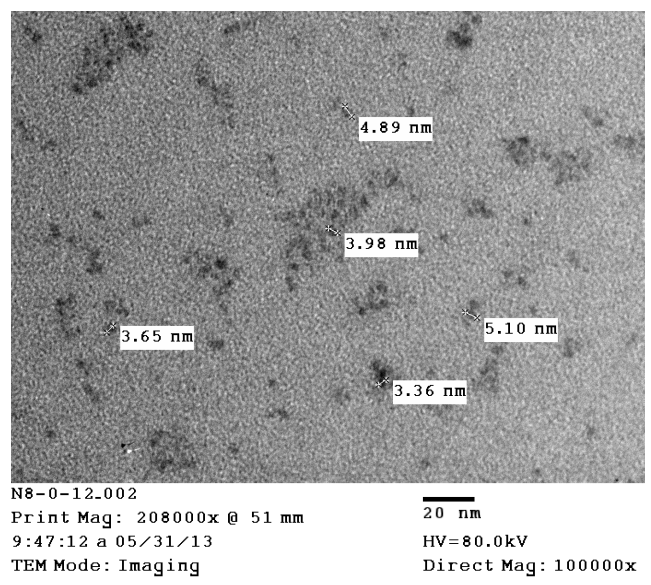

(a)

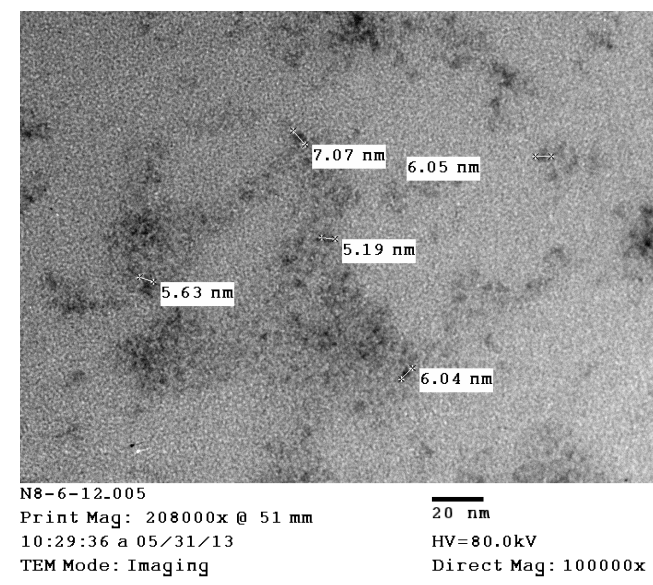

(b)

Fig. 3. TEM images of $\mathrm{Cd}_{0.2} \mathrm{Zn}_{0.8} \mathrm{Se}$ core (a) and core/shell TQDs (b). 
The composition of the TQDs samples measured by EDS indicates that subsequent incorporation of zinc into the crystal lattice takes place after reaction times larger than $18 \mathrm{~min}$ and that the formation of $\mathrm{Cd}_{0.2} \mathrm{Zn}_{0.8}$ Se alloy nanocrystals is observed. Elemental analysis of the TQDs reveals the presence of $\mathrm{Zn}$, $\mathrm{Cd}$, and Se in the TQDs core and the presence of the $\mathrm{Zn}$ and $\mathrm{S}$ elements in the shell. Thank to the superior optical properties of the alloy crystal structure, the $\mathrm{Cd}_{0.2} \mathrm{Zn}_{0.8} \mathrm{Se} / \mathrm{ZnS}$ 6 ML TQDs were selected for the biosensor fabrication.

Fig. 5 shows the absorption and PL spectra of $\mathrm{CdZnSe} / \mathrm{ZnS}$. The PL spectrum under the excitation wavelength of $442 \mathrm{~nm}$ exhibits an emission peak at $568 \mathrm{~nm}$ with FWHM of about $34.4 \mathrm{~nm}$. The excitonic absorption peak at $556 \mathrm{~nm}$ and the strong PL peak at $568 \mathrm{~nm}$ of TQDs show the eligible optical properties to build biosensor. Moreover, one of the criteria for the biosensors based on quantum dots is minimizing

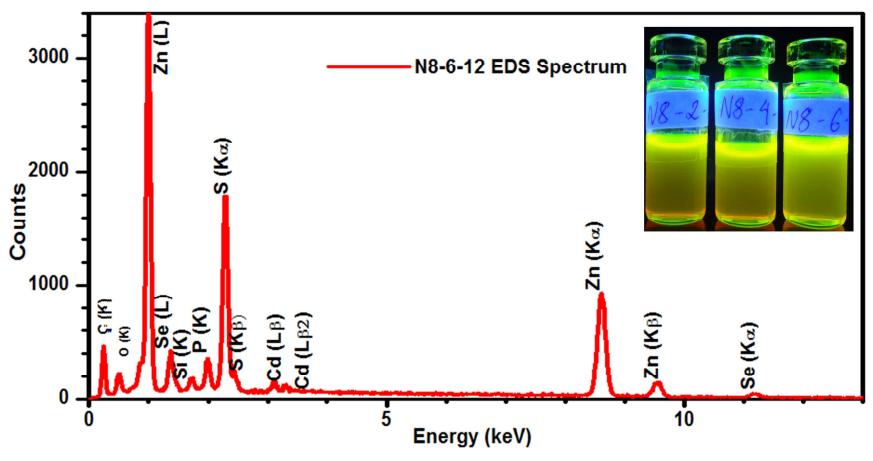

Fig. 4. EDS spectrum of $\mathrm{Cd}_{0.2} \mathrm{Zn}_{0.8} \mathrm{Se} / \mathrm{ZnS}$ 6ML core/shell TQDs.

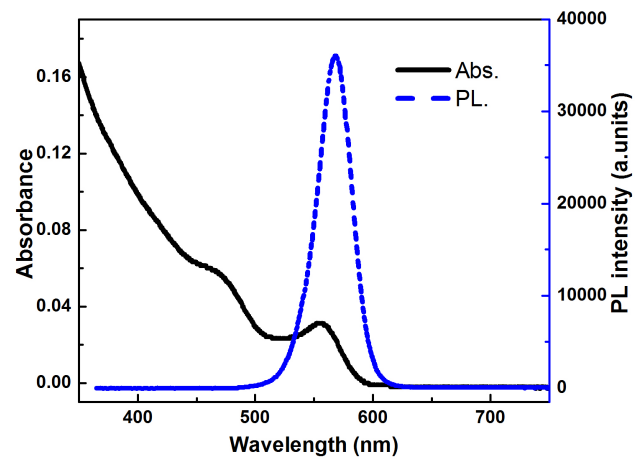

Fig. 5. Absorption (solid) and PL (dotted) spectra of CdZnSe/ZnS blinking effect. This directly affects the "in" and "out" signals of the quantum dots acting as the transducers [11]. For the CdZnSe/ZnS 4ML sample, the time traces and the blinking are quite better than the CdSe/ZnS nanocrystals. We find that, on the average, the nanocrystals spend $35 \%$ in the ON time. More specifically, about one third of them are in the ON state more than $50 \%$ of the time, and about one third of them are in the ON state less than $20 \%$ of the time [12].

In this biosensor structure, ATCh acts as an indicator for the presence of the AChE enzymatic activity, while the TQDs act as the luminescence indicators for the hydrolysis of ATCh. Eventually, the luminescence from TQDs can indicate the AChE enzymatic activity or correspondingly the pesticide content because of adding pesticide into the mixed solution. The pesticide would bind and inhibit the AChE enzymatic activity.

AChE enzyme catalyzes the hydrolysis of ATCh to produce TCh, which bears an additional thiol group (?SH) to possibly decrease the $\mathrm{pH}$ surrounding the TQDs (Fig. 6). Fig. 7a shows the result of specific amount of $100 \mu \mathrm{l}$ TQDs, $122 \mu \mathrm{l}$ AChE and $16.7 \mu 1$ ATCh, we observed the PL intensity of TQDs/AChE/ATCh solution decreased, and it takes 12 min to reach the stable value. The solution of ATCh/CH 2 ppm was mixed separately from the TQDs/AChE. The integrated PL 
intensity was measured increasing 1.75 times for $26 \mathrm{~min}$, illustrated in fig $7 \mathrm{~b}$. Based on the mechanism, two types of organophosphorus (cypermethrin- $\mathrm{CH}$ ); carbamate (abamectin-AT) pesticides were detected on tealeaves.

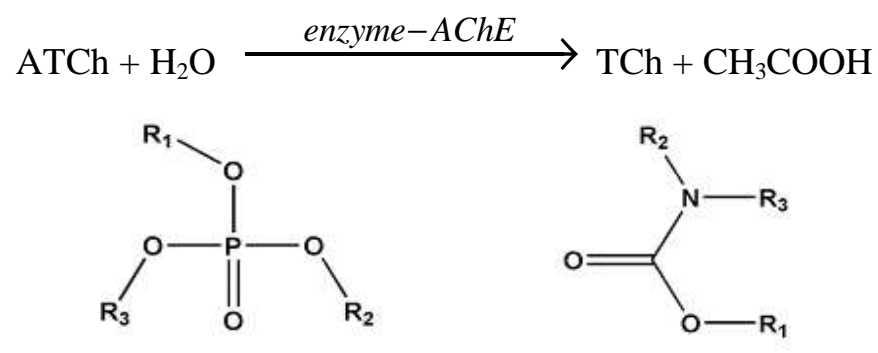

Fig. 6. General chemical structures for the most popular categories of AChE inhibitors, namely organophosphates (left) and carbamates (right)

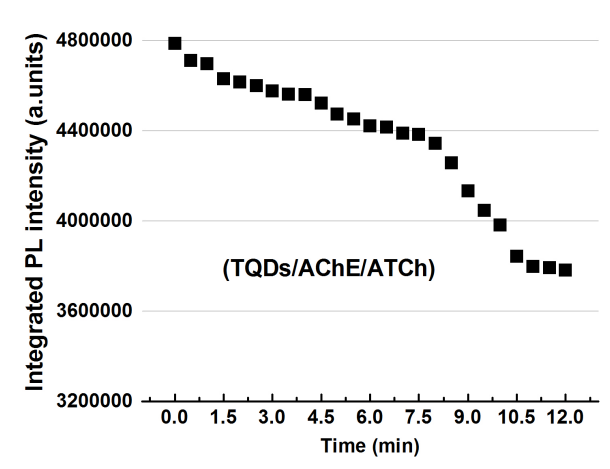

(a)

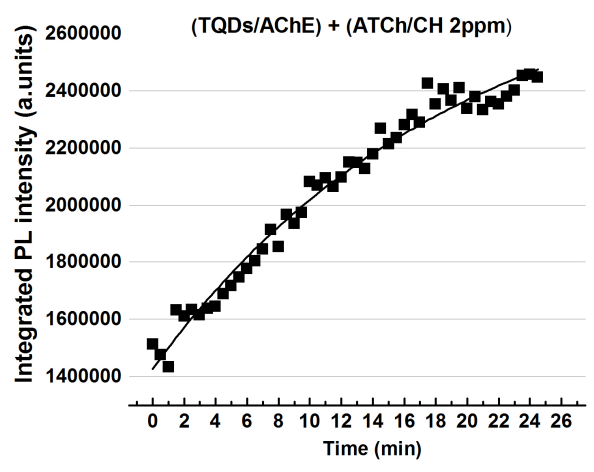

(b)

Fig. 7. The changes in fluorescence intensity over time of TQDs /AChE/ATCh

Figures 8 and 9 present the same trend of PL intensity decreased with the time in 14 and 7 days. The $\mathrm{pH}$ values were measured at the temperature of $30.7 ? 31.0 \mathrm{oC}$. The maximum $\mathrm{pH}$ value of TQDs/AChE initially is about 10.30-11.37 and decreased with the time to 4.16-4.45. It is meaning that the concentrations of pesticides are also decrease. The integrated PL intensity of the corresponding concentrations is shown in figures 8, 9 (right). Considered the initial fluorescence intensity in the absence of pesticide residues is $100 \%$, we have measured and calculated the percentage decrease of fluorescence intensity over time, at the end of duration the percentage of fluorescence decrease to 40.7-50.8\%. Moreover, by theoretical speculations, we have assigned the pesticide concentrations corresponding to the initial fluorescence intensity of the initial mixture before spraying, concentrations of pesticide residues in tealeaves have fallen each day, and the concentration at the time of the last survey are about 0.05-0.02 ppm, (Table 1). 


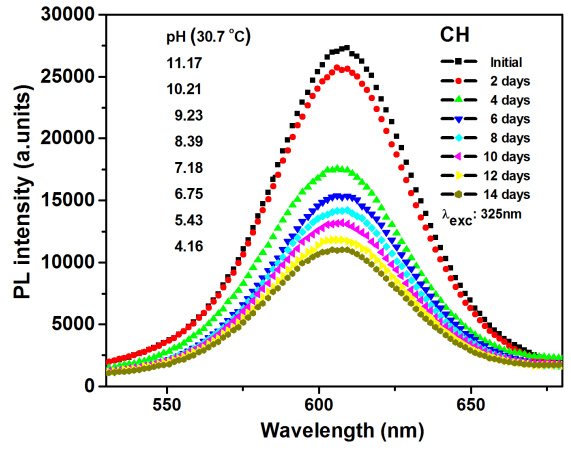

(a)

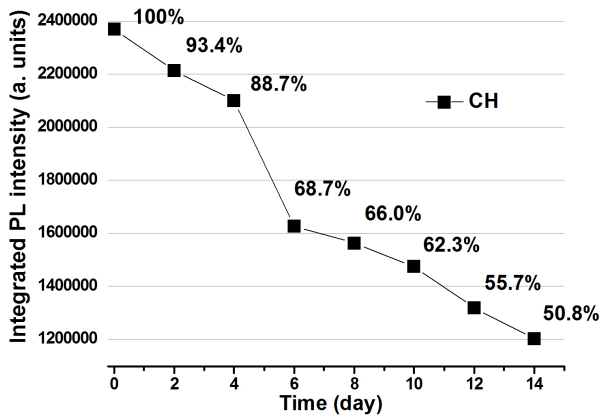

(b)

Fig. 8. Fluorescence spectra of the biosensor (TQDs/AChE) with $\mathrm{CH}$ as a function of time (left), and the time dependence of integrated PL intensity (right).

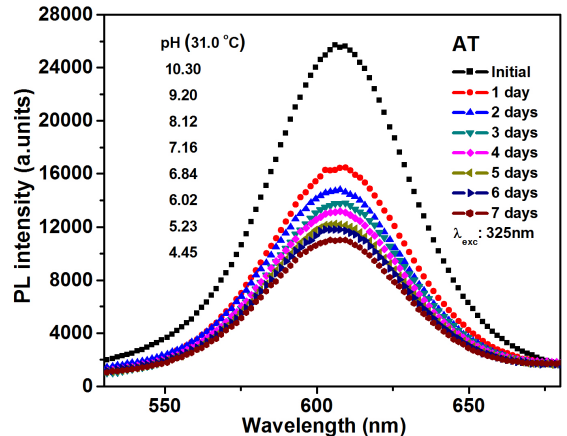

(a)

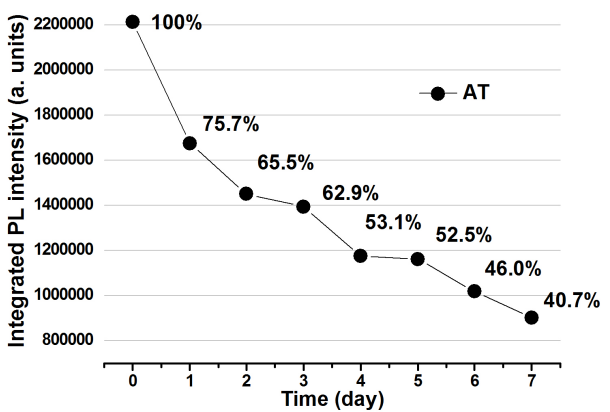

(b)

Fig. 9. Fluorescence spectra of the biosensor (TQDs/AChE) with AT as a function of time (left), and the time dependence of integrated PL intensity (right).

Table 1. The decreasing percentage of PL intensity and corresponding pesticide residue concentrations.

\begin{tabular}{ccccccccc}
\hline $\mathrm{CH}(\%)$ & 100 & 93.4 & 88.7 & 68.7 & 66 & 62.3 & 55.7 & 50.8 \\
\hline $\mathrm{CCH}(\mathrm{ppm})$ & 0.71 & 0.66 & 0.59 & 0.40 & 0.27 & 0.17 & 0.09 & 0.05 \\
\hline AT $(\%)$ & 10075.7 & 65.5 & 62.9 & 53.1 & 52.5 & 46 & 40.7 & \\
\hline CAT $(\mathrm{ppm})$ & 1.12 & 0.85 & 0.56 & 0.35 & 0.19 & 0.10 & 0.04 & 0.02 \\
\hline
\end{tabular}

The pesticides might interact with the activity center of AChE preventing acetic acid production. On the contrary, if the number of protons $(\mathrm{H}+)$ were generated more by acetic acid ( $\mathrm{pH}$ decreased), the $\mathrm{H}+$ can capture the electron $\left(\mathrm{e}^{-}\right)$on the surface of the TQDs decreasing the $\mathrm{e}-\mathrm{h}$ recombination in TQDs and causing PL quenching of the biosensor [13]. For quantum dots 
passivated with an inorganic capping layer, the TQDs core is often assumed isolated from the outside environment, leading to the expectation that the TQDs photoluminescence should not be affected by external factors. However, MPA-capped core/shell TQDs are highly sensitive to $\mathrm{pH}$ : fluorescence increases in intensity and slightly shifts toward the longer wavelength side with increasing $\mathrm{pH}$. The decrease of fluorescence intensity with decreasing $\mathrm{pH}$ has also been reported for $\mathrm{CdSe} / \mathrm{ZnS}$ binary quantum dots [14].

\section{CONCLUSION}

CdZnSe/ZnS TQDs have been successfully fabricated. The TQDs exhibit emitting the light in the visible region with less blinking effect and a surface area large enough to conjugate with biological agents to form biosensors.

We have confirmed that the TQDs emission depends not only on the particle size but also the component percentage. We can quantitatively control the pesticide residues on tealeaves over time in sunny weather conditions. The pesticide concentrations ranged from $0.05 \mathrm{ppm}$ to 0.02 ppm within permissible limits and do not affect the health of users.

\section{ACKNOWLEDGMENT}

This research is funded by NAFOSTED under grant number 103.06-2011.03, the PICS- no 5724 and the support for young researcher from IMS-VAST. The authors thank the National Key Laboratory for Electronic Materials and Devices-IMS for the supplying the facilities. We sincerely thank Prof. Nguyen Quang Liem for his judicious discussions.

\section{REFERENCES}

[1] R. Buiculescu, M. Hatzimarinaki, and N. A. Chaniotakis, Analytical and Bioanalytical Chemistry 398 (7-8) (2010) 3015-3021.

[2] Y. P. Chen, B. Ning, N. Liu, Y. Feng, Z. Liu, X. Liu, and Z. X. Gao, Journal of Environmental Science and Health Part B 45 (6) (2010) 508-515.

[3] B.-M. Kim, A. Abd El-Aty, T.-E. Hwang, L.-T. Jin, Y.-S. Kim, and J.-H. Shim, Bulletin of the Korean Chemical Society 28 (6) (2007) 929-935.

[4] A. P. Periasamy, Y. Umasankar, and S.-M. Chen, Sensors 9 (6) (2009) 4034-4055.

[5] P. T. Nga, V. D. Chinh, P. T. Linh, K. C. Cuong, V. T. H. Hanh, N. X. Nghia, C. Barthou, and A. Maitre, Adv. Nat. Sci. 10 (2009) 167-174.

[6] P. Nga, V. Chinh, V. Hanh, N. Nghia, P. Dzung, C. Barthou, P. Benalloul, J. Laverdant, and A. Maitre, International Journal of Nanotechnology 8 (3) (2011) 347-359.

[7] A. Chen, D. Du, and Y. Lin, Environmental Science \& Technology 46 (3) (2012) 1828-1833.

[8] Q. Chen and Y. Fung, Electrophoresis 31 (18) (2010) 3107-3114.

[9] Y. Chen, H. 1. Ren, N. Liu, N. Sai, X. Liu, Z. Liu, Z. Gao, and B. a. Ning, Journal of Agricultural and Food Chemistry 58 (16) (2010) 8895-8903.

[10] G. Mercey, T. Verdelet, J. Renou, M. Kliachyna, R. Baati, F. Nachon, L. Jean, and P.-Y. Renard, Accounts of Chemical Research 45 (5) (2012) 756-766.

[11] N. N. Hai, V. D. Chinh, T. K. Chi, U. T. D. Thuy, N. X. Nghia, D. T. Cao, and P. T. Nga, Key Engineering Materials 495 (2012) 314-318.

[12] N. N. Hai, V. D. Chinh, U. T. D. Thuy, T. K. Chi, N. H. Yen, D. T. Cao, N. Q. Liem, and P. T. Nga, International Journal of Nanotechnology 10 (3) (2013) 137-145.

[13] K. Paek, S. Chung, C.-H. Cho, and B. J. Kim, Chem. Commun. 47 (37) (2011) 10272-10274.

[14] N. H. Nguyen, T. G. Duong, V. N. Hoang, N. T. Pham, T. C. Dao, and T. N. Pham, Advances in Natural Sciences: Nanoscience and Nanotechnology 6 (1) (2015) 015015. 